\title{
Reply to Tin and Wiwanitkit
}

\author{
Frederick M. Burkle, Jr, MD, MPH, DTM
}

Y

our comments are most welcome and I agree, multiple issues arise in control and containment that clinicians and decision-makers have little experience with. For all practitioners, those public health skills are fundamental. They must be equally translatable to every patient as well as to decisions made by the broad international community. Collaboration and cooperation is essential. One reason Ebola has spread so easily in Liberia is the rapid urbanization and density of the population from Monrovia to the northern counties. The Hajj is another timely example because the population density has increased every year with more attendees from around the world. The decision to prevent attendees from West Africa this year is a correct one that is unavoidable in the larger triage system necessary in epidemics and pandemics.

\section{About the Author \\ Harvard Humanitarian Initiative, Harvard University, Cambridge, Massachusetts, and Woodrow Wilson International Center for Scholars, Washington, DC. \\ Correspondence and reprint requests to Frederick M. Burkle, Jr, $\mathrm{MD}$, Harvard Humanitarian Initiative, 14 Story Street, 2nd Floor, Cambridge, MA 02138 (e-mail: fburkle@hsph.harvard.edu).}

Published online: January 2, 2015. 